\title{
Los ministerios y el clero
}

\section{José María Castillo \\ Centro de Reflexión Teológica, \\ San Salvador.}

El punto de partida de cuanto voy a decir en este trabajo es un hecho tan conocido como doloroso para la Iglesia: en los últimos veinticinco años, han abandonado el ministerio ordenado más de 95,000 clérigos. Por otra parte, la crisis de vocaciones sacerdotales se ha hecho sentir en casi todas las diócesis y congregaciones religiosas, de tal manera que muchos serninarios y noviciados han cerrado o se han visto reducidos a su mínima expresión. De ahí que el número de sacerdotes ha descendido de manera alarmante en casi toda la Iglesia. Hasta el punto de que hoy son muchos los pueblos y partoquias que se tienen que quedar sin misa los domingos. $\mathrm{Y}$ hay pequeñas poblaciones, sobre todo en América Latina, en donde sólo se celebra la eucaristía dos o tres veces al año. Por otra parte, es frecuente el caso de sacerdotes que tienen que celebrar hasta cuatro o cinco misas los domingos, con el consiguiente peligro de rutina y cansancio por parte del celebrante, que no puede preparar a los fieles y dedicar a la celebración el tiempo y la atención que merece.

Por otra parte, esta situación tiende a agravarse en la Iglesia. La media de edad del clero ha aumentado de manera alamante, de forma que en muchas diocesis esa media de edad está muy por encima de los 50 años. Lo cual quiere decir que, o se da un inesperado crecimiento de vocaciones sacerdotales, o en los próximos veinte años el número de sacerdotes en la Iglesia se va a ver reducido drásticamente, creando situaciones absolutamente insoportables para los fieles.

Otro capítulo en todo este asunto lo constituyen las críticas que hay contra el clero. Es verdad que muchas de esas críticas provienen del anticlericalismo, tan introyectado en no pocos ambientes de nuestra sociedad. Pero aun reconociendo eso, no cabe duda de que son muchas las personas de buena voluntad que se sienten profundamente identificadas con Cristo y con el evangelio, pero no están 
de acuerdo en absoluto con el clero y con su manera de actuar1. Esto supuesto, aquí se plantean cuestiones muy fundamentales: ¿es el clero de institución divina?, ¿es lo mismo hablar del clero que hablar de los ministerios en la Iglesia?, ¿se puede concebir una Iglesia con ministerios variados, pero sin clero?, ¿qué es lo aceptable y qué es lo que no se debe aceptar en la realidad del clero tal como existe en la actualidad? Más aún, ies realmente posible una Iglesia verdaderamente liberadora con un clero como el que existe en la actualidad?

Evidentemente, al formular estas preguntas estamos planteando cuestiones muy fundamentales para la vida de la Iglesia. En definitiva, se trata de comprender qué es lo inmutable en el ministerio eclesial y qué es lo que puede - y quizá se debe- cambiar en dicho ministerio.

\section{Lo inmutable en el ministerio eclesial}

El ministerio eclesial es esencial en la Iglesia porque es esencial en ella la apostolicidad. Y la apostolicidad exige la sucesión apostólica, que históricamente se ha dado y se da en la sucesión episcopal2. Por eso la jerarqula pertenece a la estructura divina de la Iglesia. Lo cual quiere decir que la existencia de ministros, oficialmente establecidos en cada comunidad eclesial, es un dato que pertenece a la estructura misma de la Iglesia. Y, por tanto, que la presencia de tales ministerios, en cada comunidad eclesial, es un hecho y un elemento que no debe faltar en una comunidad de creyentes en Jesús. Por eso, cuando digo que en las comunidades cristianas tiene que haber ministerios y ministros, oficialmente establecidos, quiero decir que ese hecho es un asunto que no pertenece solamente a la organización de la Iglesia y de cada comunidad, sino que, antes que eso, se trata de un elemento esencialmente constitutivo de la estructura misma de la Iglesia. De tal manera que si una comunidad rechazase, no ya a tal ministro determinado, sino el hecho mismo del ministerio, dejarla de ser, por eso mismo, una verdadera comunidad eclesial3.

Pero lo dicho necesita una mayor concreción. Ante todo, es importante tener en cuenta que el ministerio oficial de la Iglesia se caracteriza, entre otras cosas, por los poderes que le son propios. Estos poderes, según la conocida doctrina del Concilio de Trento, son el poder de ofrecer y presidir la eucarístia y el poder de perdonar sacramentalmente los pecados 4 . Como es sabido, en la actualidad hay téblogos que defienden la posibilidad de que un laico presida la eucaristla, cuando una comunidad eclesial se encuentra en la situación excepcional de no poder disponer de un ministro ordenado para dicha presidencias. La autoridad eclesiástica no admite esta posibilidad. Y en todo caso, es necesario tener presente la enseñanza del Concilio Vaticano II según el cual "el sacerdocio común de los fieles y el sacerdocio ministerial o jerárquico se ordena el uno al otro, aunque cada cual participa de forma particular del único sacerdocio de Cristo. Su diferencia es esencial, no sólo gradual"6. Y el mismo concilio entiende esta 
diferencia en el sentido de que el sacerdocio ministerial "efectúa el sacrificio eucarístico", mientras que los fieles, "en virtud de su sacerdocio real, asisten a la oblación de la Eucaristía"7.

Por lo demás, todo este lenguaje conciliar queda abierto a ulteriores precisiones, ya que utiliza la palabra "sacerdote", para referirse a los ministros de la Iglesia. Pero sabemos que este lenguaje es ajeno al Nuevo Testamento, que, como explicaré más adelante, evita cuidadosamente aplicar el término "sacerdote" a los ministros de la comunidad cristiana. Lo cual quiere decir obviamente que "lo sacerdotal", en cuanto "lo sacral" y contrapuesto a lo profano, no pertenece a lo inmutable en el ministerio eclesial.

Lo inmutable, en este ministerio, es la existencia de obispos, en cuanto sucesores de los apostoles. Y la existencia también de ministros, que han recibido la imposición de manos del obispo y, en consecuencia, están capacitados para presidir la celebración eucarística y para perdonar sacramentalmente los pecados.

Ahora bien, esta realidad, inmutable y simple, de lo que es el ministerio eclesial en sí, se puede llevar a la práctica y se puede vivir de muchas maneras. Concretamente, se puede vivir bajo dos formas fundamentales: o bien haciendo que el conjunto de los ministros de la Iglesia formen un cuerpo de funcionarios de la institución eclesiástica, en cuyo caso tenemos el clero; o bien permitiendo que los ministros de la Iglesia vivan en la libertad de los hijos de Dios, sin más exigencias que las que se derivan directamente de su servicio (ministerio) a la comunidad, bajo la presidencia y dirección, desde la fe, del obispo respectivo. En este caso, no tendrfamos un clero, sino simplemente los ministerios que necesita la comunidad.

En principio, esta distinción nos puede resultar extraña, quizá sorprendente, incluso imposible. Tan acostumbrados estamos a identificar clero con ministerios, que la separación de ambas cosas nos parece imposible. Sin embargo, baste recordar que, en los escritos del Nuevo Testamento, se habla ampliamente de ministerios, pero no se menciona para nada el clero. Y no es cuestión de palabras, como enseguida vamos a ver.

Obviamente, el planteamiento, que acabo de enunciar, lleva consigo la desaparición de la distinción entre ministerios clericales y ministerios laicales. Todos los ministerios deben ser laicales, es decir ministerios del laos, del pueblo de Dios. Puesto que el clero, en el sentido que voy a explicar y con las precisiones que voy a hacer, debe desaparecer.

Pero insisto - perdónese la redundancia- en que no se trata de poner en cuestión la estructura jerárquica de la Iglesia. Ni tampoco de negar la necesidad de ministros que, mediante la imposición de manos del obispo, quedan capacitados para consagrar la eucaristía y para perdonar sacramentalmente los pecados. 
No se trata, por tanto, de rechazar la distinción essentia et non gradu entre los ministros que han recibido la imposición de manos y los que participan del sacerdocio común de los fieles. De lo que se trata es de volver a la inspiración original del Nuevo Testamento. Para asi descubrir la verdadera autenticidad del ministerio eclesial. Y encontrar también un camino de solución al gravísimo problema, que se le ha planteado a la Iglesia con la crisis que vive el clero.

\section{De los ministerios al clero}

Como es bien sabido, el Nuevo Testamento no habla de "sacerdotes" como dirigentes de las comunidades eclesiales, ni se refiere para nada al "orden" o a los "ordenados" en la Iglesia, ni alude en absoluto al celibato eclesiástico, ni indica cómo tienen que ser designados y preparados los ministros de la comunidad, y menos aún trata el tema de cómo tienen que ser las relaciones económicas entre el obispo y los presbíteros. Esta situación se mantiene asl durante todo el siglo segundo. Por supuesto, yo sé muy bien que no podemos pedirle al Nuevo Testamento lo que éste no puede dar. Y sobre todo, estoy perfectamente persuadido de que la vida de la Iglesia no se rige por la sola letra de la Biblia, ya que la tradición y el desarrollo dogmático son un enriquecimiento para aqué1la. Todo esto es claro y no admite discusión. Pero lo que aquí hay que preguntarse es si la evolución que se produce, desde los ministerios del Nuevo Testamento al clero que surge siglos más tarde es una evolución coherente con lo que fue la inspiración original del cristianismo o es, más bien, un proceso de degeneración de lo que fue aquella originalidad de la primera hora. El análisis, que voy a hacer a continuación, nos ofrecerá los elementos de juicio necesarios para poder responder a esta cuestion, que es la cuestión central en todo este asunto.

He dicho que el clero es el resultado de la evolución del ministerio. Esta evolución fue lenta y tardó más de setecientos años en cuajar plenamente. Pero hoy estamos en condiciones de describir los elementos que intervinieron en esta evolución y que dieron como resultado esta institución concreta que es el clero. Los pasos que se dieron en esta evolución fueron los siguientes.

\subsection{El sacerdocio}

Hoy sabemos con toda seguridad que el Nuevo Testamento evita cuidadosamente llamar sacerdotes a los ministros de las comunidades cristianas. $Y$ en general se evita el vocabulario sacral para designar a los ministros. Es decir, no se trata meramente de un argumento "de silencio", en el sentido de que el Nuevo Testamento no habla de "sacerdotes" como dirigentes en la Iglesia. Se trata, sobre todo de que los autores del Nuevo Testamento evitan cuidadosamente llamar sacerdotes a los ministros de las comunidades8. Esta situación se mantiene asl durante todo el siglo segundo9. Hasta que en el siglo tercero Hip6lito, en la Tradición Apostólica10, Tertulianoll y, sobre todo, Cipriano, en 147 tex- 
tos 12 , utilizan la palabra "sacerdote" para referirse a los ministros de la Iglesia. A partir de entonces, esta designación se generaliza.

Lo imporlante aquí es comprender que no se trata de una mera cuestión de vocabulario. Si los autores del Nuevo Testamento expresamente no quisieron llamar "sacerdotes" a los ministros de la Iglesia, eso quiere decir que aquellos autores comprendieron que esa palabra es inadecuada para expresar lo que son los ministros de la comunidad cristiana. En efecto, "sacerdote" es una palabra "sagrada", que expresa una condición y una cualificación "sagrada", y que se aplica a las personas separadas y segregadas de las demás, a los que se considera "profanos". Además, la condición "sacerdotal" comporta una "dignidad" y un "honor", y por lo tanto, el sacerdote es el que está por encima de los demás. Sin olvidar que el "sacerdote" entraña la condición de "mediador" entre Dios y los hombres.

Ahora bien, todo esto exactamente es lo que quisieron evitar los autores del Nuevo Testamento. Porque, para ellos, el ministerio eclesial es un "servicio" (diakonía) y una "esclavitud" (doulía) 13, o sea, lo más radicalmente opuesto a una dignidad y un honor.

La razón profunda de este planteamiento está en lo que, de hecho, fue el sacerdocio de Cristo: él no vino para ser servido, sino "para servir y dar su vida" (Mc 10, 44; Mt 20, 27). Esto quiere decir, según la carla a los Hebreos, que el sacerdocio de Cristo no fue ritual, sino existencial. Es decir, lo que Cristo ofreció no fue una ceremonia ritual dignificante, sino el fracaso y la muerte de un subversivo, que desestabilizó la religión y el sistema establecido. Por eso, el sacrificio cultual de los cristianos es la misma existencia de Cristo (Heb 2, 14; $5,7-8 ; 7,27 ; 9,9-14 ; 10,5-9 ; 12,2)$, de tal manera que el mismo Cristo es la nueva víctima sin mancha que sustituye a todas las demás ofrendas (Heb 4, 14; 9, 14; 10,6-7); y la oblación cultual del cristianismo es, ni más ni menos, el sufrimiento de Jesús (Heb 2, 18; 5, 9), que es el único mediador. Por consiguiente, en la Iglesia, no hay más "dignidad" ni más "honor" sacerdotal que el que consiste en el servicio, en la entrega de la propia vida y en el fracaso de un ajusticiado. En esto consiste el sacerdocio de Cristo. Pero, es claro, a esla cruda realidad no se le puede llamar "sacerdocio" como categorfa dignificante de los que presiden en la comunidad.

Y sin embargo, en la Iglesia se ha impuesto "lo sacerdotal" como categorfa que separa, que pone aparte, que dignifica y da honor, que sitúa a un individuo por encima de los demás cristianos, que cualifica y confiere derechos y privilegios. De esta manera, los que detentan esta dignidad excelsa se sienten, inevitablemente, por encima de los demás. Y forman una casta aparte, la casta sacerdotal. A todo lo cual hay que añadir el hecho de que los "sacerdotes" se constituyen en "mediadores", siendo asi que el único "mediador" es Cristo. 
He aquf, pues, la primera característica del clero, que no arranca del Nuevo Testamento, sino que está al margen de él. Así empezó el proceso de degeneración del ministerio eclesial. Así, el servicio y la esclavitud se convirtieron en honor y dignidad. De tal manera que, con un lenguaje sacral y religioso, en realidad lo que se estaba expresando era y es un proceso de mundanización. La adulteración del ministerio empezaba a ser patente.

\subsection{El orden}

Hoy estamos acostumbrados a hablar del "sacramento del orden". Y lo consideramos de institución divina. Por eso hablamos de los "ordenados" como lo más natural en la Iglesia. Sin embargo, aqul hay que hacer una distinción fundamental: una cosa es la imposición de manos como gesto sacramental mediante el cual se confiere el ministerio, y otra cosa es el ordo y la ordinatio como realidad sobreañadida al ministerio. Y vuelvo a decir que no se trata de una cuestión de palabras. Se trata de realidades muy profundas, como enseguida vamos a ver.

De nuevo hay que advertir aquí que el Nuevo Testamento no habla ni de ordo, ni de ordinatio, ni de ordinati. Los autores de aquel tiempo sabían muy bien lo que significaban esas palabras. Y por eso las evitaban. En efecto, ordo y ordinatio eran, en aquel tiempo, conceptos clave en la organización de la sociedad y del imperio 14, porque eran los téminos clásicos para designar el nombramiento de los funcionarios imperiales, sobre todo cuando se trataba del emperador mismo. Lo cual indica claramente la tendencia de los ministros eclesiales a distanciarse del pueblo y a acomodarse, en la medida de lo posible, a los notables y grandes de la sociedad. Pero no se trata solamente de eso. Porque, además el ordo lenía, en el imperio romano, la significación secundaria de clase social, de tal manera que existían tres ordines: el de los senadores (ordo senatorum), el de los caballeros (ordo equitum) y el de la plebe o pueblo llano (ordo plebeius). $Y$ es importante tener en cuenta que, en las comunidades cristianas, se asumí esta terminologla precisamente para diferenciar netamente a los ministros (ordenados) del resto de la comunidad y la comunidad misma. Los "servidores" de la comunidad pasaron a ser los notables y los que dominaban a la misma comunidad.

Estas ideas sobre el "orden" y la "ordenación" se introducen, en la Iglesia en tiempo de Tertulianols y adquieren carta de ciudadania en tiempo de Ciprianol6. Pero de tal manera que, para Tertuliano, la diferencia entre los "ordenados" y la "plebe" es el resultado de una decisión eclesiástical7, mientras que para Cipriano, unos años más tarde, esta diferencia es una disposición divinal8.

Asf, el ministerio eclesial vino a sufrir una nueva modificación: los ministros de la comunidad se consideraron en un orden superior a la comunidad y se constituyeron en centro de la misma. De esta manera, la Iglesia se dividió en dos categorfas de personas: los "sacerdotes ordenados", como la categorfa superior, 
con responsabilidad y mando; y la plebe o los laicos como la clientela consumidora de los servicios religiosos que los dirigentes ponfan a disposición de los fieles. Había nacido el clero.

Aquí es importante notar que mientras en las iglesias que aparecen en el Nuevo Testamento el centro de cada una es la comunidad toda entera, en las iglesias del siglo tercero, el centro ya es el "sacerdocio ordenado". Antes de Constantino ya se produjo la inversión que dio el cambio radical a la Iglesia. Y es obligado recordar que, en algunos casos, se llegó a verdaderas aberraciones. Por ejemplo, la Didaskalía, en el siglo tercero, llega a exaltar hasta tal punto al obispo, que lo compara con Dios y lo sitúa en lugar de Dios. En este sentido, los textos resultan sorprendentes: "El primer sacerdote y levita para ustedes es el obispo; él es el que les imparte la palabra y es su mediador...; él reina en lugar de Dios y ha de ser venerado como Dios, porque el obispo les preside en representación de Dios"19. Y más adelante: "Estimen al obispo como la boca de Dios"20. Más aún: "Amen al obispo como padre, témanle como rey, hónrenlo como Dios"21. Aqul ya no se trata de una sacralización de los "sacerdotes ordenados", sino de una auténtica divinización. Por eso, lo característico del obispo no es el servicio y la entrega, sino la potestas o exousia, de tal manera que al obispo se le dice lo siguiente: "Juzga, obispo, con polestad como Dios"22. Más no se puede decir en esta verdadera apoteosis de exaltación y hasta divinización del clero. Evidentemente, todo esto no tiene que ver nada con la letra y el espíritu del Nuevo Testamento.

\subsection{El celibato}

No voy a repetir aquí una historia que ya es de sobra conocida23. Sólo quiero hacer algunas indicaciones que me parecen importantes.

En cuanto a la enseñanza del Nuevo Testamento, lo primero que hay que decir es que san Pablo permaneció soltero, con vista a una mayor disponibilidad para la misión (cfr. ICor 9,$23 ; 7,32$ ). Pero el caso de Pablo, al igual que el de Bemabé, fue una excepción, ya que en la primera carta a los Corintios 9, 5 el mismo Pablo afirma que los demás apóstoles, incluido Cefas, iban acompañados por una mujer creyente, que sin duda tenía que ser su esposa. Y conste que el texto afirma que esto era un derecho que tenían los ministros del evangelio. Por otra parte, en las cartas posteriores se dice que los presbíteros-obispos tienen que ser esposos de una sola mujer ( $1 \operatorname{Tim} 3,2$; Tit 1,6), es decir, maridos fieles 24 , y tienen que educar bien a sus hijos (1Tim 3, 4; Tit 1,6). Como indica A. Lemaire, el autor de estas epistolas prescinde de la cuestión del celibato en lo que respecta a los ministros de la Iglesia; para él, el estado normal del "presbítero-epíscopo" es el de casado y con hijos2s.

Como es sabido, a partir del siglo cuarto (Concilio de Elvira), se impone a los ministros la obligación de la continencia matrimonial. Los presbíteros y 
diáconos estaban casados, pero desde la ordenación como diáconos (a los 30 años) se tenían que separar de sus legítimas esposas en cuanto se refiere a la vida conyugal. La razón de esta medida fue la interpretación sacral, porque se tenía el convencimiento de que la sexualidad impurifica para la oración y el acercamiento al altar. Es decir, desde el momento en que se consideró a los ministros de la Iglesia como "sacerdotes", o sea, personas "sagradas", resultaba lógica la imposición de la continencia sexual. Siglos más tarde, en el Segundo Concilio de Letrán (año 1139), la ley de la continencia se convierte en la ley del celibato: a los ministros se les prohibe casarse y se declara nulo el matrimonio de los ordenados in sacris. Por lo que se refiere a los obispos, se les prohibió el matrimonio además por razones económicas: para evitar que los bienes de la Iglesia pasaran a los sucesores, hijos o nietos.

Evidentemente, la historia del celibato eclesiástico pone de manifiesto la visión tan negativa, que ha tenido la Iglesia acerca de la sexualidad humana. Dos ejemplos nada más. En el siglo XI, cuando aún se les permitía a los ordenados in sacris estar casados y sólo se les prohibía llevar vida conyugal con sus legítimas esposas, san Pedro Damián dice lo siguiente: “¿Cómo no violará el templo de Dios aquel a quien se prohibe el comercio carnal, si se construye a sí mismo como prostrbulo de petulante lujuria? Arroja de sí al Espíritu Santo en el que había sido signado y en su lugar introduce el espíritu de la libido"26. Y en el siglo XII, el Segundo Concilio de Letrán, en el Canon 6, al privar de oficio y benefício eclesiástico a los clérigos que tomasen esposas, les dice lo siguiente: "pues debiendo ser y parecer como templo de Dios, vasos del Señor, sagrario del Espíritu Santo, es indigno que sirvan a las camas y las inmundicias".

No cabe duda. Con visión tan negativa de la sexualidad, la institución eclesiástica no podía permitir que sus ministros llevaran vida matrimonial. Pero han pasado muchos años y los tiempos han cambiado. Hoy la Iglesia aprecia el matrimonio y predica que el amor conyugal es algo santo y digno de toda estima. Entonces, ¿por qué empeñarse en seguir con la ley del celibato como ley absolutamente obligatoria para todos los clérigos de la Iglesia latina? Sin duda alguna, yo creo que inconscientemente sigue influyendo la antigua visión pesimista de la sexualidad. Pero aparte de eso, pienso que existe una razón muy poderosa para imponer el celibato a todos los clérigos: una institución, cuyos funcionarios son célibes, se domina y se maneja con más facilidad y con más eficacia que una institución cuyos funcionarios son casados. No digo que este principio actúe a niveles conscientes. No lo sé. Por supuesto, de este asunto no se habla jamás en los discursos oficiales y en los documentos eclesiásticos. Pero es indudable, desde mi punto de vista, que el criterio, que acabo de apuntar, está presente y operante en la negativa de la autoridad eclesiástica a reconsiderar la conveniencia o inconveniencia de mantener, a toda costa, la ley del celibato obligatorio para todos los "sacerdotes" de la Iglesia latina. 
$Y$ pienso que no es difícil justificar el principio que he apuntado antes. Empezando por lo más elemental: un conjunto de funcionarios célibes resulta más barato que un conjunto de funcionarios casados, con hijos y con obligaciones familiares. El valor económico es determinante en este asunto, aunque la mayor parte de las veces ni siquiera se piensa en ello. Por otra parte, es evidente que un individuo célibe es más manejable que un individuo casado. Al soltero se le puede cambiar de destino y, en general, es más sumiso que el que tiene que cumplir con otras fidelidades, concretamente la fidelidad a la esposa y a los hijos. En el lenguaje eclesiástico, se suele hablar, cuando se toca este punto, de disponibilidad para el servicio del reino de Dios. Y no cabe duda que una persona célibe está en condiciones de tener una disponibilidad y unas posibilidades que, por lo general, no puede tener el casado. Pero si el verdadero problema fuera realmente la disponibilidad, los dingentes eclesiásticos, o sea, los que defienden a capa y espada la ley del celibato, empezarían ellos los primeros por dar ejemplo, yéndose a servir al reino en el último rincón de la tierra en vez de permanecer en sus cargos y destinos de privilegio. Así las cosas, a cualquiera se le ocurre pensar que en este asunto de la ley del celibato juega un papel decisivo el conocido privilegio psicológico según el cual, quien domina la sexualidad de una persona, domina y maneja más lácilmente a esa persona. Así, la ley del celibato es ley de poder. La institución, de esta manera, maneja, controla y domina a sus funcionarios con una seguridad, una facilidad y una eficacia que no se daría si los clérigos estuvieran casados.

Por supuesto, los principios y motivos teológicos que se aducen en favor de la ley del celibato, son principios y motivos de un alto valor religioso, al menos en muchos casos y en líneas generales. Pero lo que habría que demostrar es que esos principios y esos motivos justifiquen una ley universal y obligatoria para todos los que se sienten llamados al ministerio. Ahora bien, esto hasta ahora no se ha dernostrado con el Nuevo Testamento en la mano. Ni creo que se pueda demostrar. Más bien, lo que el Nuevo Testamento nos dice es lo contrario. Y en todo caso, se puede y se debe afirmar que la institución eclesiástica no tiene derecho a dejar a tantos cristianos sin el auxilio de la Palabra y sin el servicio de los sacramentos, para mantener una ley humana de la que se sigue inevitablemente una falta de ministros para atender debidamente a las comunidades eclesiales.

En definitiva, se trata de comprender que, por un camino nuevo, nos hemos encontrado, otra vez, con la distinción y la distancia que separa a los ministerios del clero. El ministerio es el servicio en una Iglesia cuyo centro es la comunidad. El clero es el cuerpo de funcionarios en una Iglesia cuyo centro es el mismo clero. $Y$ ha quedado claro que la ley del celibato es una de las piezas clave de este cuerpo de funcionarios. 


\subsection{La designación de los ministros}

Por los datos que nos aporta el Nuevo Testamento, parece que la designación de los ministros en la Iglesia primitiva era el resultado de un acuerdo entre el candidato, la comunidad y los otros ministros ${ }^{27}$. Así en el caso de Timoteo (1Cor 4, 17; 16, 10; Flp 2, 19) y en el de Tito (2Cor 8, 16-19). En cambio, Epafrodito es designado por la comunidad de Filipos y Pablo se limita a aceptarlo (Flp 2, 25). Lo fundamental es que lo mismo el candidato que la comunidad y los ministros estén de acuerdo en la designación. En cualquier caso, es decisivo el papel de la comunidad, como consta por la Didajé $(X V, 1 s)$ y por el texto de Hechos 6, 3: "Hermanos, busquen especialmente entre ustedes siete hombres de buena reputación". Ya antes, Matías había sido elegido por volación popular (Hch 1, 26). Como sabemos igualmente que Bernabe y Saulo fueron enviados a la misión por toda la comunidad de Antioqula (Hch 13,2-3). Sin duda alguna, ésta fue la práctica normal de la Iglesia durante los siglos primero y segundo.

A comienzos del siglo tercero afirma la Tradición Apostólica de Hipólito: "Que se ordene como obispo al que ha sido elegido por el pueblo, que es irreprochable... con el consentimiento de todos"28. Años más tarde, exactamente en el 250, en la persecución de Decio, hubo tres obispos españoles, los de León, Astorga y Mérida, que negaron la fe y dieron malos ejemplos a los fieles. Ante semejante escándalo, las comunidades afectadas depusieron a los mencionados obispos. En tal situación, uno de ellos. Bashides, acudió al papa Esteban, que lo repuso en su diócesis. Pero la comunidad, que estaba en desacuerdo con semejante decisión, acudió a Cipriano, obispo de Cartago y hombre de eminente prestigio en las iglesias de España. Dada la gravedad del asunto, Cipriano reuni6 un concilio en el que participaron 37 obispos. Este concilio dio un decreto que se contiene en la Carta 67 de Cipriano. En sustancia, la carta viene a decir tres cosas: en primer lugar, el pueblo tiene poder, por derecho divino, para elegir a sus ministros 29 ; en segundo lugar, el mismo pueblo tiene también poder para quitar a los ministros cuando son indignos30; y en tercer lugar, ni el recurso a Roma debe cambiar la situación, cuando ese recurso no se basa en la verdad31. Como se ve, la organización eclesiástica, en aquellos tiempos, era muy distinta de la que se implanta a partir del segundo milenio. El centro de la vida de la Iglesia estaba en la comunidad, de tal manera que el mismo Cipriano afirma con toda naturalidad: "Desde el principio de mi episcopado determiné no tomar ninguna resolución por mi cuenta sin vuestro consejo y el consentimiento de mi pueblo"32. Y es que durante todo el primer milenio, el principio rector, en la designación de los ministros de la Iglesia, era el formulado magistralmente por san León Magno: "El que debe ser puesto a la cabeza de todos, debe ser elegido por todos"33. Es más, se tenía el firme convencimiento de que el obispo no debía ser impuesto a quienes no lo aceptaban, puesto que se requería el consentimiento del clero y del pueblo. Así lo formuló el papa Celestino I en una frase que se hizo famosa y que pasó al Decreto de Graciano: Nullus invitis detur 
episcopus. Cleri, plebis et ordinis, consensus ac desiderium requiratur.

Esta forma de designar a los ministros de la comunidad se mantuvo así, con toda regularidad, hasta el siglo XI. A partir de Gregorio VII, se inicia la larga serie de intervenciones papales en las que los romanos pontfices van interviniendo, cada vez más, en el nombramiento de los obispos. Hasta que finalmente el Concilio de Trento, en los decretos de reforma, dio por supuesto y decidido que los obispos eran designados por la autoridad romana, marginando así definitivamente a la comunidad 34 .

El hecho fuerte que aparece en esta historia es que la institución eclesiástica actuó de tal manera, que se pasó del protagonismo de la comunidad hasta la anulación de la misma. Dicho de otra manera: la institución clerical asumió la responsabilidad y el protagonismo en el nombramiento de sus funciones. De esta forma, los funcionarios perdieron inevitablemente libertad y pasaron a depender más radiçalmente de la autoridad suprema. Lo cual, a su vez, comportaba y comporta un control mayor del vértice de la piránide sobre lodos sus subordinados.

Pero no es esto sólo. Porque, en el clero, el problema no es solamente el acceso al ministerio. El clero está organizado de tal manera que en él se dan, de hecho, una serie de promociones, nombramientos y ascensos, que van desde el incipiente coadjutor de parroquia hasta el gran honor del episcopado e incluso hasta la gloria del cardenalato. Ahora bien, todo esta carrera de posibles ascensos no depende de un escalafón reglamentado, sino siempre de la voluntad del superior 35 , sobre todo de la voluntad de la autoridad romana, que, a través de sus nuncios, sus diversos dicasterios y su complicado sistema de informes secretos, controla a sus funcionarios de una manera eficacísima. De todo lo cual resulta una consecuencia inevitable: con bastante frecuencia, los clérigos se preocupan más por no desagradar al superior del que dependen que por servir con libertad evangélica a la causa del reino de Dios. Así, la institución eclesiástica gana en eficacia y en control sobre sus subordinados, pero pierde inevitablemente en coherencia evangélica. De nuevo nos encontramos con la sustitución y la distancia que separa el clero del ministerio original de la Iglesia.

\subsection{La cuestión económica}

Todos sabemos que las relaciones económicas juegan un papel muy importante en la vida. ¿Cómo funciona este asunto entre los clérigos?

Lo primero que se debe recordar a este respecto es que el Nuevo Testamento reconoce el derecho que tiene el ministro de la comunidad a vivir de su ministerio (ICor 9, 13-14; Mt 10, 10; Lc 10, 7). Pero al mismo tiempo hay que recordar también los numerosos textos en que San Pablo afirma que él renuncia a ese derecho para no crear dificultades al evangelio (1Cor 9, 12; 1Tes 2, 9; 4, 10ss; 
2Tes 3, 6-12; 1Cor 4, 12; 9, 4-18; 2Cor 11, 7-12, 13-18; Hch 20, 3 3-35; cfr. Hch 18, 1-4). Esta abundancia de documentación demuestra que este asunto era importante para Pablo. Y en el fondo nos viene a decir que el mismo Pablo reconocía que el derecho a vivir del ministerio puede ser un obstáculo para la comunicación del evangelio. De ahí la opción de vivir de un trabajo secular. Por eso, parece que en las comunidades primitivas los ministros de las iglesias locales continuaban ejerciendo su profesion, como en el caso de Priscila y Aquila "fabricantes de tiendas de campaña" (Hch 18, 3).

Sin duda alguna, este estado de cosas, se mantuvo asl durante mucho tiempo. En la alta edad media, los clérigos que no disfrulaban de un beneficio suficiente trabajaban como todo el mundo. En el año 1139, el Segundo Concilio de Letrán manda que "los presbíteros, clérigos, monjes, peregrinos, comerciantes y campesinos, que se dedicaban a la agricultura, y llevan al campo semillas y ovejas, estén seguros en todo tiempo"36. La misma legislación se encuentra en el Concilio de Clermont (año 1130) ${ }^{37}$ y en el Concilio de Reims (año 1131)38. Por tanto, es claro que todavía en el siglo XII, los clérigos (al menos muchos de ellos) se ganaban la vida con el sudor de su frente.

Pero algunos años más tarde, en 1179, el Tercer Concilio de Letrán modificó sustancialmente esta situación. En efecto, este concilio decretó que "el obispo, si ordena a alguno de diácono o de presbítero sin un beneficio cierto del cual perciba lo necesario para la vida, le proporcione lo necesario, hasta que en alguna iglesia se le asigne el dinero conveniente para la milicia clerical; a no ser que quien es ordenado goce de una herencia suficiente para vivir"39. En realidad, lo que aqur se legisla es más importante de lo que parece a primera vista. Porque esta ley vino a modificar y sustituir lo que hab́a decretado el Concilio de Calcedonia, que en su Canon 6 declaró inválidas las llamadas "ordenaciones absolutas", es decir aquellas ordenaciones en las que un sujeto era ordenado sin relación a una comunidad concreta 40 . En el fondo, esto quería decir que solamente se consideraba ministro verdadero y válido de la Iglesia aquel que era llamado y aceptado por una comunidad. Pues bien, este principio, esencialmente comunitario, fue sustituido en el Tercer Concilio de Letrán por el principio económico de la conveniente sustentación del clérigo41.

De esta manera, la comunidad cristiana quedó nuevamente marginada y en su lugar se estableció el principio según el cual los clérigos pasaron a depender económicamente de la institución eclesiástica. De lo cual se siguieron dos consecuencias prácticamente inevitables. En primer lugar, en el estado clerical entraron muchos individuos que lo que querfan era vivir sin trabajara2, con la consiguiente degeneración de costumbres en el estamento eclesiástico. En segundo lugar, al depender los clérigos económicamente de los obispos, estos ejercieron un control mucho más fuerte sobre el clero. Porque, inconscientemente, las relaciones entre el obispo y los clérigos no eran ya relaciones basadas 
únicamente en la fe, sino que, además de eso, eran relaciones económicas, por más que ni siquiera se pensara en ese asunto. Y como la relación económica es lo que más radicalmente pervierte toda relación evangélica (cfr. Mı 6, 19-24), así los clérigos no sólo se vieron más limitados en su libertad, sino que además se pervirtieron, muchas veces inconscientemente, en sus relaciones de fe. Por decirlo con claridad: de esta manera, en el clero entró mucha gente que lo que, en el fondo, quería era hacer carrera. Y a decir verdad, muchos, efectivamente, lo consiguieron.

En la actualidad, la mayor parte de los obispos no suelen consentir que sus clérigos ejerzan profesiones civiles. El argumento de los obispos es que los hombres de Iglesia deben dedicarse, a tiempo completo, al ministerio y al servicio de las almas. Pero es indudable que, en todo este asunto, influye también, de manera decisiva, el motivo económico: evidentemente, un individuo, que tiene su economía resuelta independientemente del obispo, es más difícilmente manejable que el que depende del prelado en sus ingresos. Y es claro, los obispos no suelen querer prescindir de este mecanismo de control que les facilita el gobierno de sus diócesis.

Por otra parte, es claro que muchas de las tareas que ahora desempeña el clero podrían ser realizadas por la comunidad, si los clérigos renunciaran a ser el centro de todo, en la vida de la Iglesia, y si la comunidad tuviera mayor responsabilidad y participación efectiva en la gestión de los asuntos.

\section{Conclusiones}

1. El ministerio eclesial es esencial en la Iglesia y pertenece a su estructura divina e inmutable. La apostolicidad de la Iglesia comporta la sucesión apostólica, que históricamente se ha dado en la sucesión episcopal. Ministros de la Iglesia no son solamente los obispos, sino también los presbiteros, que mediante la imposición de las manos de los obispos reciben los poderes de presidir y consagrar la eucaristía; y también de perdonar sacramentalmente los pecados. Por tanto, la diferencia entre los ministros oficiales de la Iglesia y los demás fieles es esencial y no meramente gradual.

2. En la Iglesia y en la teologf́a católica se suele identificar el ministerio con el clero, porque se suele considerar que el clero es el desarrollo natural y positivo del ministerio del Nuevo Testamento. Pero cuando se piensa de esa manera no se tiene debidamente en cuenta que el clero se ha configurado historicamente por unas caracteristicas que, de hecho, han pervertido el ministerio original de la Iglesia.

3. Estas caracteristicas son cinco. Primera, la sacralización "sacerdotal" de los ministros, que los ha situado en un rango aparte en la comunidad, otorgándoles una condición de "mediadores" con una "dignidad" y un "honor", que están 
en contra del espíritu y de la letra del Nuevo Testamento. Segunda, la elevación de los ministros a la calegoría de "ordenados", lo que significa colocarse por encima de la comunidad, constituyéndose en centro de la misma y marginando a los laicos en la vida de la Iglesia. Tercera, la imposición obligatoria de la ley del celibato, para todos los ministros de la Iglesia latina, lo que de facto está privando a muchísimos fieles de los auxilios espirituales a los que tienen derecho, y además crea una dependencia indebida de los clérigos con respecto a la institución eclesiástica. Cuarta, la marginación de la comunidad en la designación de los ministros, de tal manera que la elección y la promoción de éstos sólo depende de la voluntad del superior, lo cual fomenta en la Iglesia un tipo de relaciones que muchas veces se orienta más a no desagradar al superior que a anunciar libremente y con espíritu profético el evangelio. Quinta, la dependencia económica de los ministros con respecto a la institución eclesiástica, lo que inevitablemente pervierte evangélicamente las relaciones entre los ministros y la institución, generando el espíritu de funcionarios que, a veces de manera inconsciente y otras veces conscientemente, quieren hacer carrera.

4. Todo esto quiere decir que a la institución eclesiástica no le basta la fe para relacionarse con sus ministros. Además de la fe, necesita otros mecanismos de control, que hacen de los ministros un cuerpo de funcionarios al servicio del sistema institucional. De esta manera, la institución eclesiástica gana en eficacia lo que pierde en coherencia evangélica. De ahí, el clericalismo y el anticlericalismo que tanto daño hacen a la Iglesia.

5. Por otra parte, este sistema de funcionamiento, en la Iglesia, condena inevitablemente a los laicos a la pasividad y a la irresponsabilidad. Por mucho que se fomente la teología y la espiritualidad del laicado, este estado de cosas no cambiará en la Iglesia mientras la institución clerical permanezca intacta.

6. Todo lo dicho hasta ahora explica, al menos en parte, la prevención y la resistencia que existe, en altas esferas eclesiásticas, hacia la Iglesia "popular", las comunidades de base y en general hacia la Iglesia que nace del pueblo. Lo que en la mayor parte de los sacerdotes de la Iglesia popular se rechaza no es el ministerio del Nuevo Testamento, sino el clero. El problema, en la mayor parte de las comunidades de base, no es la Iglesia paralela, ni la desobediencia al papa y a los obispos. Las comunidades aceptan la estructura jerárquica de la Iglesia y se someten a ella. Lo que quieren estas comunidades es una Iglesia en la que el clero no tenga el protagonismo que tiene, es decir, una Iglesia cuyo centro esté real y efectivamente en el pueblo de Dios, es decir, en la comunidad con sus ministros.

7. Mientras el clero siga funcionando en la Iglesia como hasta ahora funciona, diffcilmente la Iglesia va a poder ser eficazmente liberadora. Porque la institución clerical genera unos mecanismos de protagonismo, por una parte, y de sometimiento y dependencia, por la otra, que no son fácilmente conciliables con 
lo que, de hecho, deber ser una Iglesia auténticamente liberadora.

8. Otra consecuencia que se sigue de todo lo anterior es que debe desaparecer la distinción entre ministerios clericales y ministerios laicales. En la Iglesia, todos los ministerios deben ser laicales, es decir, del laos, del pueblo de Dios.

9. En última instancia, se trata de comprender que lo que debe desaparecer es la distinción entre clérigos y laicos, en el sentido explicado. En la Iglesia sólo debe haber laicos, cada uno con su carisma y su ministerio al servicio de la comunidad, bajo la presidencia del obispo. Entre estos diversos ministerios esıará siempre el ministerio que ha recibido, mediante la imposición de manos del obispo, el poder de presidir y consagrar la eucaristía y el poder también de perdonar sacramentalmente los pecados. La vida de estos ministros no debe distinguirse de la del resto de los fieles, porque se trata de tomar en serio que todos, en la Iglesia, estamos llamados al seguimiento de Jesús y a la perfección evangélica.

\section{Notas}

1. Véase un análisis del clero y sus problemas en la obra fundamental y discutida de $\mathbf{E}$. Drewermann, Kleriker. Psychogramm eines Ideals (Olten 1989).

2. Que los obispos son "los sucesores de los ap6stoles" es un hecho afimado de tal forma por la tradición y por el magisterio de la Iglesia, que se impone como un dato de fe. La idea se encuentra ya en $1 \mathrm{Clem} 42 ;$ y la expresión aparece prácticamente desde Ireneo (Adv. Haer., II, 3 Harvey, II, 8) y Tertuliano (Praescr., 32. PL 2, 42). Tomás de Aquino, recogiendo una tradición secular, emplea frecuentemente la fórmula episcopi succesores apostolorum (IV Sent, d.7, q.3 a. 1; Quodl., XI,7; $S$ Theol. III, q.67, a.2, ad 1; q.72, a. 11c., C. Impugn, c.4; De perfect. Vitae spir., caps. $16,18,26)$. $Y$ en el magisterio eclesiástico, se encuentra en el concilio de París (829), cap. IV (Mansi 14,538), en el de Florencia (DS 1318), Trento, Ses. XXIII, cap. 4 (DS 1768), Vaticano I, ses. IV cap. 3 (DS 3061) y Vaticano II (LG I8 y 20).

3. Cfr. José M. Castillo, Para comprender los ministerios de la Iglesia (Estella 1993) 38.

4. Ses. XXIII, Can. 1, DS 1771.

5. Esta doctrina no es nueva. En el siglo III la defendla Tertuliano: cuando no hay sacerdotes ordenados, los laicos pueden bautizar y celebrar la eucaristía, porque donde hay tres allf está la Iglesia, aunque sean laicos: Ubi ecclesiastici ordinis non est consessus, et offers et tinguis et sacerdos es tibi solus; scilicet ubi tres, ecclesia est licet laici. De exhorn. cast., VII, 3 CC 1024-1025. Hay que tener en cuenta que el De exhort castitatis fue escrito entre los años 208-212, es decir, en el tiempo en que Tertuliano sufria ya la influencia montanista. Pero es importante notar que en este tiempo todavia no hab/a roto con la gran Iglesia. Cfr. R. Braun, "Deus Christianorum". Recherches sur le vocabulaire doctrinal de Tertulliem (París 1962) 567-577. Sin duda, Tertuliano alude, en este texto, a una práctica establecida entre los cristianos de su tiempo.

6. LG 10, 2. 
7. Ibid.

8. He demostrado ampliamente esta cuestión en mi libro Para compender los ministerios de la Iglesia 43-46. Véase tambiên: J. Colson,Ministre de Jésus-Christ ou le sacerdoce de L'Evangile (Paris 1966) 179ss; A. Vanhoye, Prêtres anciens prêtre nouveau Testament (París 1980) 59-64; C. Wiêner, "Ceux qui assumt le service sacré de l'évangile", en Vatican II. Les Prêtres. Famation. Ministêre et vie (Paŕs 1968) 257-259.

9. En la carta de Clemente de Roma a los cristianos de Corinto se dice que los presbiteros son "hombres que han presentado a Dios las ofrendas ('à dôra) con una piedad irreprochable" (XLIV, 4. Funk I, 156). Presentar a Dios "ofrendas" puede ser considerado como una acción sagrada y, por tanto, sacerdotal. Pero hay que tener en cuenta que clemente no utiliza el término Prosforó, sino simplemente dôra, que no es una palabra sacral, puesto que significa "dones" en general.

10. Trad. Apost., ed. B. Botte 39, 41, 66 .

II. Utiliza ocho veces la palabra sacerdos para designar al obispo: De Bapt., XVII, I: CC291, 13-14; De leium., XV1, 8CC1275, 15; De Pud., XX, 11: CC 1325, 60-61; XXI, 17: CC 1328, 79; De exhort. cast., VII,5: CCI025, 29; VII, 6: CC 1025, 30; XI, 2: CC1031, 11; VII, 2: CC 1024, 15.

12. Cfr. J. M. Castillo, Para comprender los ministerios de la lglesia, 50.

13. Diakonos es el término técnico que usa el Nuevo Testamento con más frecuencia para hablar de ministerio. Hasta 34 veces aparece esa palabra con este sentido preciso. Cfr. H. Beyer, Diakoneo: TWNT II, 81 ss.; K. Hess, Servicio, en L Coenen, E. Beyreuther, H. Bietenhard, Diccionario Teológico del Nuevo Testamento, I (Salamanca 1984) 212-216; A. Stenzel, El servicio divino de la comunidad reunida en Cristo. Culto y liturgia, en Myst. Sal., IV/2, 26-52; 178-183; 472-477; A. Lemaire, Les Minisères dans la recherche néo-testamentaire. Etat de la question. La Maison-Dieu 115 (1973) 44, con abundante bibliograffa. Doulos designa claramente el ministerio, según Mc 10, 43-44: Mt 20, 25-27. Lo cual se ve confirmado con textos tan seguros como Hch 4, 29; Flp 2, 22; 1Cor 4, 5; 9, 19. Cfr. K. H. Rengstorf: TWNT II 265ss.

14. Cfr. Pauly-Wissowa, Realencyclopddie der Klassichen Alsertumswissenschaft XVIIL/1 (Stuttgart 1939) 930-936; P. Fransen, "Ordo", LThk VII 1212-1220.

15. Por ejemplo, en De exhort. cast, VII. PL 2, 971. Para este punto, véase: P. van Beneden, Awx origines d'une ierminologie sacramentelle: Ordo, ordinatio dans la listérature latine avant 313 (Lovaina 1974); M. Bevenot, "Tertullians thoughts about the Christian priesthood", en Corona Gratiarum. Miscellanea E. Deskkers, I (Brujas 1975) 125-137.

16. En las cartas de Cipriano aparece con frecuencia la diferencia y la superioridad de los "ordenados" sobre la "plebe". Los textos, en mi obra Para comprender los ministerios de la Iglesia, 51.

17. Differentiam inter ordinem et plebem constituit ecclesiae auctoritas, De exhort. cast. VII, 3: CC 1024-1025.

18. Cum hoc ita divina lege fundatum sil, Epist. 33. Hartel CSEL 566, 12-13.

19. Didaskolia, XXVI 4, Funk 104.

20. Didask, XXVIII, 9. Funk 110

21. Didask, XXXIV, 5. Funk 118.

22. Didask, XII, 1. Funk 48. 
23. Véase un resumen de esta historia, con información bibliográlica, en mi libro Para Comprender los ministerios de la Iglesia, 79-91. Es epecialmente recomendable el estudio de R. Gryson, Les origines du célibat ecclésiastique du premier au septième siècle (Gembloux 1970).

24. Cfr. P Trummer, "Eine Ehe nach den Pstoralbriefe". Biblia 51 (1970) 47I-484.

25. A. Lemaire, "Las epístolas pastorales", en J. Delorme, El ministerio y los ministerios según el Nuevo Testamento (Madrid 1975) 107.

26. Op. XVIII, diss. II, 4. PL 145, 405.

27. Cfr. J. Coson, "Désignation des ministres dans le Nouveau testament", La MaisonDieu 102 (1970) 21-29; R. Schnackenburg, "La colaboración de la comunidad, por el consentimiento y la elección, según el Nuevo Testamento", Concilium 77 (1972) 1830.

28. Hipolito, Trad. Apost, II, ed B. Botte (Münster 1963) 5-6.

29. Quod es ipsum videmus de divina auctorifate descendere, ut sacerdos plebe praesente sub omnium oculis deligasur es dignus adque idoneus publico indicio ac testimonio comprobetur, Cipriano, Epist. 67, 4: CSEL 738, 3-5.

30. Propter quod plebs obsequens proeceptis dominicis et Deum metuens a peccatore proeposito separare se debet, nec ad sacrilegi sacerdotis sacrificia miscere, quando ipsa maxime habeat potestatem vel eligendi dignos sacerdotes vel indignos recusandi, Cipriano, Epist. 67, 3: CSEL 737-738, 20-22.

31. Nec rescindere ordinationem iure peffectam protest quod Basilides post crimina sua detecta el conscientiae etiam propriae confessione nudata Romana pergens Siephanum collegam nostrum longe positum et gestae rei ac verisasis ignarum fefellit, ut exambires reponi se injuste in episcopatum de quo fuerat iure depositus, Cipriano, Epist. 76; CSEL 739, 18-24.

32. Cipriano, Epist. 14, 4: CSEL 512, 18-20. cf J. I. González Faus, Hombres de la comunidad. Apuntes sobre el magisterio eclesial (Santander 1989) 104-105.

33. Qui praefuturus est omnisbus, ab omnibus eligatur, León Magno, Epist. X, 6: PL 54, 634A.

34. Celestino I, Epist. IV, 5: PL 50, 434B; Decreto de Graciano, c. 13, D. LXI. Friedberg, 231. Cf. J. A. Estrada, La identidad de los laicos, (Madrid 1990) 128, con bibliografía abundante.

35. La historia de este proceso nos es bien conocida. $Y$ ha sido perfectamente resumida y analizada por J. I. González Faus, "Ningún obispo impuesto" (San Celestino, papa). Las elecciones episcopales en la historia de la Iglesia (Santander 1992), especialmente 127-139.

36. Conc. Lateranense II, can. II. Consilionun Oecumenicorum Decreta, ed. J. Alberigo, (Basiliea 1962) 175.

37. Can. 8. Mansi 21, 439.

38. Can. 10. Mansi 21, 460.

39. Can. 5. Conciliorum Oecumenicorum Decreta, 190.

40. Conciliorum Oecumenicorum Decreta, 66. Para un estudio de este asunto, cfr. E. Schillebeeckx, El Minisierio eclesial. Los responsables en la comunidad cristiana, (Madrid 1983) 67-83; C. Vogel, "Vacua manus impositio: l'inconsistence de la chirotonie en Occident", en Mélanges liturgiques offerts au $R$. P. Dom B. Botse (Lovaina 1972).

41. Bibliograffa sobre este asunto, en E. Schillebeeckx, o. c., 102, nota 56. 
42. Asf lo reconoce, para la edad media, H. Jedin, “ ¿Ha creado el concilio de Trento la imagen modelo del sacerdote?", en J. Coppens. Sacerdocio y celibato (Madrid 1971) 87-88. 